\title{
MAPS AND FIGURES
}

$$
\text { Maps }
$$

1. Location of Dar'ul Islam Base Areas, May 1954

2. Areas of Dar'ul Islam Predominance in $1954 \quad 116$

3. Islamic versus Nationalist Political Party Affiliations in
1963

4. Subdistrict Political Party Affiliations in 1963

\section{Figures}

5.1 Religious Variants among the Javanese 80

5.2 Political Party Affiliation and Religious Variants 82

5.3 Items in the Scale of Religious Beliefs 90

8.1 Leadership Pyramid for the Dar'ul Islam Village 206

10.1 Leadership Pyramid for Tanggerang 248

10.2 Leadership Pyramid for Cikujang 248

10.3 Leadership Pyramid for Rancabentang 249 